\title{
Managing Jordanian nurse migration to the Gulf Cooperation Council states
}

\author{
A.H. Al-Nawafleh
}

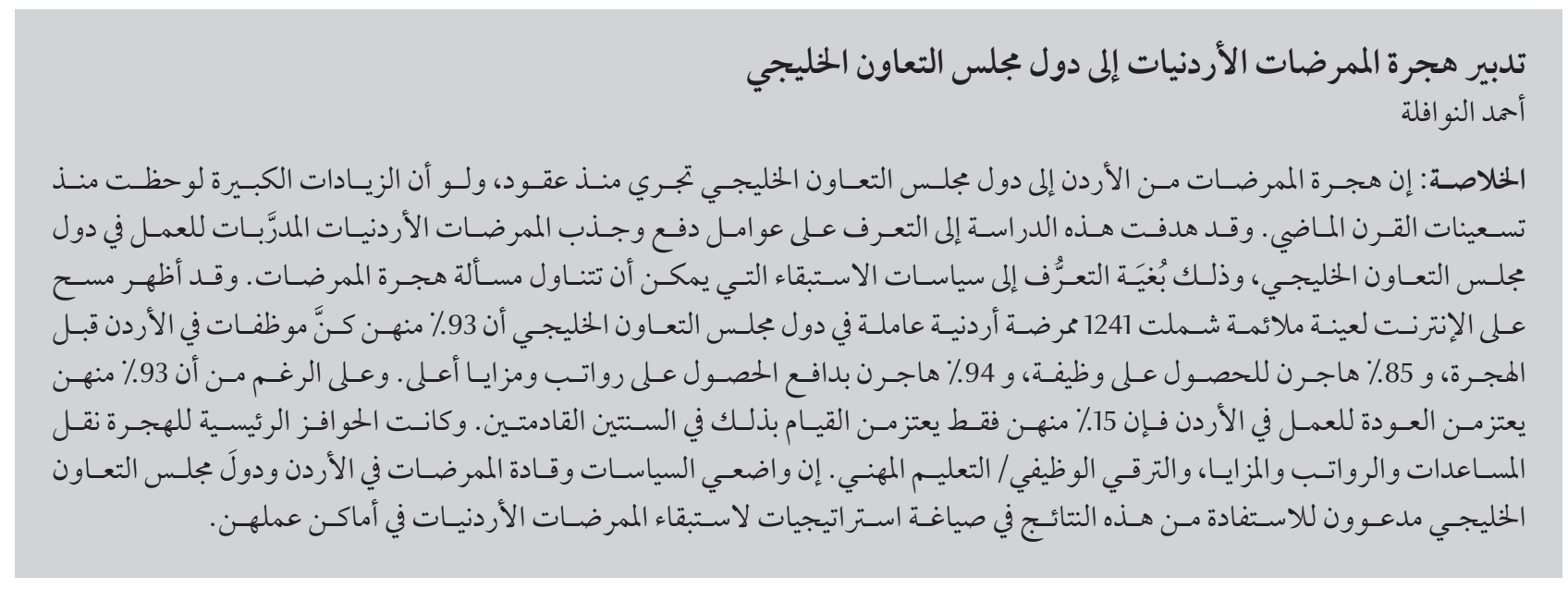

ABSTRACT The migration of nurses from Jordan to the Gulf Cooperation Council (GCC) states has occurred for decades, although substantial increases have been noted since the 1990s. This study aimed to identify the push and pull factors for Jordanian-trained nurses to work in the GCC states in order to inform retention policies that might address the issue of nurse migration. An online survey of a convenience sample of 1241 Jordanian nurses working in GCC states showed that 93\% had been employed in Jordan before migration, $85 \%$ had migrated to obtain employment and 94\% were motivated by higher salary and benefits. Although 93\% planned to return to work in Jordan, only $15 \%$ planned to do so in the next 2 years. Major incentives to migrate were relocation assistance, salary and benefits and career advancement/professional education. Policy-makers and nurse leaders in Jordan and the GCC states are urged to use these findings to formulate strategies to retain Jordanian nurses in their workplaces.

\section{Gestion de la migration du personnel infirmier jordanien vers les États du Conseil de Coopération du Golfe}

RÉSUMÉ La migration du personnel infirmier de Jordanie vers les États de Coopération du Golfe est un fait connu depuis des décennies, mais des augmentations importantes de ce phénomène ont été observées depuis les années 1990. La présente étude visait à identifier les facteurs motivant et décourageant le personnel infirmier formé en Jordanie à aller travailler dans les États de Coopération du Golfe afin d'alimenter des politiques de fidélisation qui pourraient s'attaquer au problème de la migration du personnel infirmier. Une enquête en ligne portant sur un échantillon de commodité incluant 1241 membres du personnel infirmier dans les États de Coopération du Golfe a démontré que 93 \% avaient été employés en Jordanie avant de migrer, 85 \% avaient migré pour obtenir un emploi et $94 \%$ étaient motivés par des hauts salaires et des avantages. Si $93 \%$ prévoyaient de retourner travailler en Jordanie, seuls 15 \% prévoyaient de le faire dans les deux prochaines années. Les principales incitations à la migration étaient l'assistance à la réinstallation, le salaire et les avantages mais aussi l'avancement professionnel/la formation professionnelle. Les responsables de l'élaboration des politiques ainsi que les chefs de file du personnel infirmier en Jordanie et dans les États de Coopération du Golfe sont invités à exploiter ces résultats pour formuler des stratégies visant à fidéliser le personnel infirmier jordanien à leur lieu de travail. 


\section{Introduction}

Migration of nurses is a global issue that has a considerable impact on both the sending and receiving countries (1). International and regional migration aims to restore imbalances in the nursing workforce and has both advantages and disadvantages for national health systems (2-4). The receiving country benefits because migration rectifies a shortage of locally educated nurses and helps to sustain the country's health system capacity. In contrast, although the sending country benefits from remittances from nurses abroad that help to develop its economy and increase its foreign currency accounts, migration can jeopardize its health system capacity due to the loss of health workers it has trained.

Jordan had an estimated population of 6249753 million in 2013 (5), $22 \%$ of whom live in rural areas, and an average household size of 5.4. According to the same statistics, gross domestic product per capita was US\$ 4618 and the unemployment rate was $12.9 \%$. Jordanian expatriates contribute to the economy through remittances, buying properties and creating businesses. As a result of this migration, many countries and in particular Gulf Cooperation Council (GCC) countries have substantial Jordanian communities. The target of this study was Jordanian expatriate nurses (mughtaribeen): qualified nurses of Jordanian origin who are working abroad in the GCC states and who are expected to return permanently either at expiry of a work contract or at retirement.

Jordanian workforce data indicate that there were more than 12000 registered nurses employed in Jordan in 2012, and about another 12000 associate, aid or practical nurses (6). The most recent report on Jordan's nursing workforce predicts a surplus of registered nurses that will reach 5000 by the year 2015 (6,7). In contrast, projections from the GCC states estimate nursing shortages in these countries. The urgency with which the GCC states are recruiting international nurses to cope with nursing shortages is evident $(8,9)$. The most recent Saudi health statistics suggest that there were 134632 nurses in the country in $2011,66.4 \%$ of whom were expatriates $(8,10)$. Another Saudi statistic also indicates that both the private and public sectors are employing more expatriate nurses (8). Accordingly, there is a need for policy-makers and health-care leaders to understand and act on the factors that may influence Jordanian nurse migration.

Previous research has indicated that migrant nurses experience a range of "push" and "pull" factors to seeking work abroad (2-4). Theories of human and social capital provide a framework for the study of nurse migration, as they emphasize that individuals migrate for employment and remuneration that is appropriate to their education $(11,12)$. Jordanian nurses possess skills, experience and knowledge that have a cost-benefit value to themselves as individuals as well as to the health-care systems of Jordan and the GCC states (11). Sudden movements of experienced and qualified nurses abroad may adversely affect the health services in Jordan. The objective of this study was to identify the push and pull factors for Jordanian-trained nurses working in the GCC states, in order to inform decision-making about local retention policies that might address the issue of nurse migration.

\section{Methods}

\section{Study design}

This study was conducted in the period between July 2013 and March 2014 using a cross-sectional survey. It employed gate-keepers and snowball sample techniques to reach the participants because of the difficulty of identifying and accessing the population $(13,14)$. This study was reviewed and approved ethically by Mutah Faculty of Nursing
Research Ethics Committee. There are no conflicts of interest to report related to conducting and reporting the results of this study.

\section{Sampling}

The study population was all nurses from Jordan working in GCC states (i.e. Saudi Arabia, United Arab Emirates, Qatar, Oman, Bahrain and Kuwait). Following research ethics board approval from the Faculty of Nursing, University of Mutah, electronic social networks and researcher email contacts were used to invite Jordanian nurses to take part in the study. All the initial contacts identified were asked to facilitate the study and to forward invitations to their contacts who were Jordanian nurses. Moreover, the researchers' friends and colleagues were asked to assist in this process. Attempts to access Jordanian nurses in Kuwait and Bahrain were less successful, as the researcher had no direct contacts (gate-keepers).

The confirmed and documented invitations sent either by the researcher or the gate-keepers directly exceeded a total of 1600 . However, according to the gate-keepers' reports and the researcher $\log$ data abroad, more than 3500 Jordanian nurses received the invitation. Those who responded to the invitation were asked to fill an online survey. The web link of the survey was accessed 3269 times, of which the researcher received 2039 responses from Jordanian nurses working abroad. Any responses with $>15 \%$ missed data were excluded and the database finally yielded 1241 (61\%) usable questionnaires.

\section{Data collection}

Sauermann and Roach's protocol for online survey administration was employed with participants, who were provided with a link for a web questionnaire (15). The questionnaire was designed and published online using Google surveys (http://www.google.com).

The 72 -item survey used in this study was pilot tested and utilized with a 
sample of Jordanian nurses employed in the United Kingdom (UK) and GCC states. The survey included questions related to the nurses' demographic information, views and experiences of migration, barriers to working abroad as a health professional, decision to migrate to work in the GCC states, current work characteristics and plans for returning to work in Jordan. The piloting of the survey was carried out on a small sample ofJordanians in the UK and in the GCC states to check the respondents' understanding of the each item of the survey. Data collected during the pilot stage were used only to make some modifications to the words and the order of the items in the survey. For example, some items of demographic data were moved to the end of the questionnaire because they were less likely to be answered when assigned at the beginning.

\section{Data analysis}

Online Google survey and Microsoft Excel databases were used to enter and to save responses. SPSS version 17 software was used in the analysis of the quantitative survey data and to characterize the sample of Jordanianeducated registered nurses in different GCC states. Descriptive analysis using frequencies and percentages were mainly used.

\section{Results}

\section{Respondents' background data}

Demographic and work data for the sample of Jordanian nurses who responded to the survey are displayed in Table 1. All study respondents were registered nurses, and the average age of participants was 34 years. Only one-fifth of the samplewere females while the rest were males (some did not indicate their sex). Three-quarters of the respondents were married. Three-fifths of the sample were baccalaureate-prepared, and more than one-tenth had a Master's level or doctoral education. Less than one-fifth had a nursing diploma degree.

Some of the respondents held more than one nursing position. Almost half of the participants were employed in direct patient care roles, while a quarter held nursing management or educational positions and the remainder were in advanced nursing practice roles. More than two-fifths had $>10$ years' of work experience, and more than a third had 5-10 years' of experience. The remaining one-fifth had $<5$ years' of nursing experience.

\section{Respondents' motivations and experience of migration to the GCC states}

At the time of the survey around half of the study participants were employed in Saudi Arabia $(n=638 ; 51 \%)$, followed by the United Arab Emirates $(n=382$;
31\%), Qatar ( $n=147 ; 12 \%)$, Oman ( $=38 ; 3 \%)$ and the remainder in Kuwait and Bahrain $(n=36,3 \%)$. Overall 20\% reported that they had worked in more than one GCC state. The pattern of migration of Jordanian-educated nurses over the years is shown in Table 2; $41 \%$ of the study respondents had migrated to the GCC states in the 1990s and early 2000s and a similar percentage after 2008 (42\%). Most of them had nursing employment in Jordan prior to migrating to the GCC states to work.

Respondents indicated their main motivation for moving to the GCC states from a list of reasons (plus an open section for comments). Most of the respondents left Jordan for higher salaries and benefits (94\%), while $40 \%$ expected to advance their career, $54 \%$ had a desire to travel and a small

\begin{tabular}{lcc}
\hline Table 1 Demographic data of the respondents $(\boldsymbol{n}=\mathbf{1 2 4 1})$ & & \\
\hline Demographic variables & No. & $\%$ \\
Sex & & \\
Female & 248 & 20 \\
Male & 827 & 67 \\
No response & 166 & 13 \\
Marital status & & \\
$\quad$ Married & 914 & 74 \\
Single & 135 & 11 \\
No response & 462 & 37 \\
Education & & \\
Diploma & 173 & 14 \\
Baccalaureate & 736 & 59 \\
Master's degree & 129 & 10 \\
Doctoral degree & 22 & 2 \\
No response & 181 & 15 \\
Nursing position & & \\
Direct patient care & 614 & 49 \\
Nursing management and education & 312 & 25 \\
Advanced nursing practice & 207 & 17 \\
More than one & 68 & 5 \\
$\quad$ No response & 40 & 3 \\
Experience (years) & & \\
$<5$ & 269 & 22 \\
5-10 & 437 & 35 \\
$>$ 10 & 506 & 41 \\
$\quad$ No response & 29 & 2 \\
\hline
\end{tabular}


proportion had personal or family reasons (10\%) (Table 2).

Many of the nurse participants in this study (87\%) had received financial incentives in terms of salary and benefits, although relocation assistance had been received by less than half the nurses (43\%) as a part of their move to work in the GCC states. Around one-fifth (19\%) indicated that a career advancement/professional educational incentives were provided on migration (Table 2).

Most of nurses in this study (93\%) planned to return to work in Jordan in the future, although only $15 \%$ of migrant nurses planned to do so over the next 2 years.

A high proportion of respondents (46\%) reported high satisfaction levels with their jobs and work in the GCC states.

\section{Discussion}

Although motivating factors to work outside Jordan have been studied several times from the perspectives of nursing students and nurses working in the country, there are no data and information about Jordanian nurses after they leave the country. There are gaps in knowledge about the real factors rather than the intentions that influence the ongoing migration of Jordanian nurses to the GCC states. This study attempted to achieve this by surveying the Jordanian nurses in their destination countries.

The results of this study show that nurses from Jordan continue to search for work in the GCC states; while many of the respondents to the survey had migrated before 2003, a high proportion had migrated relatively recently, since 2008. Consistent with human and social capital theories, nurses in this research were pulled to the GCC states mainly to have a higher income $(11,12)$. Other push and pull factors included the desire to travel and career advancement, which echo the results of other studies of Jordanian nurses and students $(3,7)$. This is similar to studies which suggested that nursing is seen as a mobile profession with work opportunities tied to travel $(2,6,16,17)$. It is likely that the similarities in language, culture and religious beliefs between Jordan and the GCC countries are key factors in pulling the nurses. There was a high proportion of married nurses in the sample (74\%) who had taken their spouse and children with them. This finding is not unexpected considering the tendency of young early-career nurses to seek marriage once they secure sufficient income (16).

Job dissatisfaction was possibly one reason why many respondents (93\%) stated that they were planning to return to Jordan and some had the intention to return within the next 2 years, indicating that nurses had chosen to return regardless of the push and pull factors that motivated them initially to migrate. Although some nurses were receiving

incentives and continuing education opportunities from their employers, nurses' comments provided some evidence that incentives promised at recruitment had not materialized.

Jordanian nurses in this study migrated primarily to Saudi Arabia and the United Arab Emirates, the GCC states that are projected to have the highest nursing labour force needs in the future (18,19). A number of factors may explain this. First, Saudi Arabia is the largest country of the GCC states in terms of population and health sector $(8,10)$. In addition, Saudi Arabia has good control of consumer prices and fewer risk of increased expenses; these factors influence nurse's savings and consequently the remittances they can send home. Saudi Arabia is also closer geographically to Jordan and is known as a travel destination because of the holy Islamic sites in Mecca and Medina.

Interestingly from a decision-making and policy perspective, almost all of the respondents - over 93\% — had

\begin{tabular}{|c|c|c|}
\hline Variable & No. & $\%$ \\
\hline \multicolumn{3}{|l|}{ Date of migration to GCC states } \\
\hline Before 2003 & 506 & 41 \\
\hline Between 2003 and 2008 & 184 & 15 \\
\hline After 2008 & 526 & 42 \\
\hline Moved between GCC states & 254 & 20 \\
\hline Employed as nurse in Jordan before migration & 1158 & 93 \\
\hline \multicolumn{3}{|l|}{ Reason for migration } \\
\hline To obtain employment & 1061 & 85 \\
\hline Personal reasons (family, marriage, other) & 128 & 10 \\
\hline Desire to travel & 671 & 54 \\
\hline Career advancement opportunities & 493 & 40 \\
\hline For higher salary and benefits & 1164 & 94 \\
\hline \multicolumn{3}{|l|}{ Incentives provided on migration } \\
\hline Relocation assistance & 534 & 43 \\
\hline Salary/other financial benefits & 1077 & 87 \\
\hline Career advancement/professional education & 236 & 19 \\
\hline \multicolumn{3}{|l|}{ Future plans } \\
\hline Plan to return to Jordan to work & 1156 & 93 \\
\hline Plan to return to Jordan to work in next 2 years & 192 & 15 \\
\hline \multicolumn{3}{|l|}{ Experience of migration } \\
\hline Highly satisfied with job and work in GCC states & 573 & 46 \\
\hline
\end{tabular}


been employed in Jordan prior to migrating to the GCC states. This confirms the high turnover rates reported in Jordan's health sector (20-22).

Migration to the GCC states was facilitated by financial incentives for more than half the nurses who took part in this study, and recruitment options reflect the components of human and social capital, including better payment, remuneration and resettlement assistance. Although Jordanians are known for their desire for educational opportunities, many nurses did not indicate this as a motivation to move to the GCC states (16). Of concern is the finding that the motivation for migration by most of the participants (85\%) was simply to gain employment, although around half also had aspirations to travel. This finding suggests that these nurses may have been interested in remaining in Jordan and could potentially have been retained in the country if they had satisfactory jobs with sufficient income to sustain a family $(2,3)$. A recent study among nurses employed in the southern region of Jordan reported that nurses would prefer to work in their home region and to stay in Jordan, even though they were considering migrating outside their country for employment (20).

Despite the fact that most participants reported their intention to return to Jordan to work, not many of them anticipated returning in the near future. Less than half of the nurses expressed a high level of job satisfaction, which hints at issues in their destination countries. Policy- and decision-makers in Jordan may need to look at ways to attract migrated nurses to return or to retain the current workforce inside Jordan.

The study also provided evidence about the mobility of Jordanian nurses between GCC states, as 20\% had moved between countries since migration. One can speculate that this is an indication of demand by GCC states employers; nurses may receive financial incentives to move and hence find more satisfactory positions. Nurses are likely to keep moving until they feel more valued by their employers and more satisfied with their positions (3). Return migration may not be an option as employers in Jordan maintain the same employment environment which pushed theses nurses to migrate in the first place. Employers need to take more account of the work conditions and needs of nurses to encourage then to return to Jordan.

We aimed to invite all Jordanian nurses working in the GCC states to participate in the survey. However, the difficulty of locating them and the absence of official statistics was a limit on our accessibility to nurses. Therefore, an initial email contact list were used, followed by snowball methods to increase the numbers (14). Anecdotal workforce estimates indicate there were more than 7000 Jordanian nurses living and working in the GCC states, almost half of whom were initially sampled for this study. Useable responses were received from 1241. Taking into consideration the response rate and the drawbacks of snowball sampling, the study may not be generalizable to all Jordanian-educated nurses who migrated to the GCC states. Nevertheless, the information documented in this study has implications for future research as it could ease access to participants via organizations identified as employers of a large number of Jordanian-educated nurses.

\section{Conclusions and recommendations}

The data from this study indicate that, despite relatively lower numbers between 2003 and 2008, Jordanian nurse migration to the GCC states has been active since 2008. In general, the reasons for migration are likely to continue unchanged over the course of years, in that nurses are liable to move to obtain employment and better remuneration. Although availability of nursing jobs in the GCC states for international nurses was a major push factor for Jordanian nurses, financial motives were a major pull factor in their decisions to migrate.

Given this finding, policy-and decision-makers in Jordan's health system should take into consideration the different health workforce trajectories and their impact on the quality of care provided for the country's population as well as the country's investment in nurse education. Health-care policymakers in Jordan should examine the pull factors that are offered by GCC states employers, such as a positive workplace environment, professional development and, more importantly, ways to ensure nurses have sufficient income to sustain a family, to determine whether any policy shifts in this area are needed. It is possible that similar initiatives and practices can be introduced into Jordanian health-care organizations, although some may exist that are as yet unpublished.

Data from this research provides important evidence that may have implications for policy-makers in Jordan to reformulate nursing recruitment and retention policies. Explicit employment and retention policies to regulate the flow of Jordanian nurses to the GCC states are necessary to address the factors that provoke nurses to leave. Moreover, practical efforts to express Jordan's interest and commitment for employing our graduates and retaining our nursing human capital are keys for nursing workforce planning in the future.

\section{Acknowledgements}

The author would like to thank the Jordanian nurses who devoted their time and effort to share their data and perspectives on their migration experiences. Also thanks go to Dr Barbara Nichols and Dr Mohammad Hassan for their kind review and comments on the drafts of this manuscript.

Funding: None.

Competing interests: None declared. 


\section{References}

1. Benton DC, González-Jurado MA, Beneit-Montesinos JV. Professional regulation, public protection and nurse migration. Collegian. 2014;21(1):53-9. PMID:24772990

2. Dywili S, Bonner A, O'Brien L. Why do nurses migrate? A review of recent literature. J Nurs Manag. 2013 Apr;21(3):511-20. PMID:23409815

3. El-Jardali F, Murray SF, Dimassi H, Jamal D, Abualrub R, AlSurimi K, et al. Intention to stay of nurses in current posts in difficult-to-staff areas of Yemen, Jordan, Lebanon and Qatar: a cross-sectional study. Int J Nurs Stud. 2013 Nov;50(11):1481-94. PMID:23545140

4. El-Jardali F, Dimassi H, Dumit N, Jamal D, Mouro G. A national cross-sectional study on nurses' intent to leave and job satisfaction in Lebanon: implications for policy and practice. BMC Nurs. 2009;8(1):3. PMID:19284613

5. Jordan statistical yearbook. Amman: Department of Statistics; 2012.

6. Hadidi R. Human resource for health. Country profile-Jordan. Geneva: World Health Organization; 2012.

7. JNC annual report 2012. Amman: Jordanian Nursing Council; 2012.

8. Health statistical year book. Riyadh: Saudi Arabia Ministry of Health; 2011.

9. Qatar infrastructure statistics. Doha: Economic Statistics and National Accounts Department, Qatar Statistics Authority; 2012. p. 50.

10. Almalki M, Fitzgerald G, Clark M. Health care system in Saudi Arabia: an overview. EastMediterr Health J. 2011 Oct;17(10):78493. PMID:22256414

11. Kanas A, van Tubergen F, van der Lippe T. Immigrant selfemployment: testing hypotheses about the role of origin- and host-country human capital and bonding and bridging social capital. Work Occup. 2009;36(3):181-208.

12. Al Ariss A, Syed J. Capital mobilization of skilled migrants: a relational perspective. BrJManage. 2011;22(2):286-304.
13. Falzon MA. Multi-sited ethnography: theory, praxis and locality in contemporary research. Farnham, United Kingdom: Ashgate Publishing.; 2012.

14. McKenzie DJ, Mistiaen J. Surveying migrant households: a comparison of census-based, snowball and intercept point surveys. J R Stat Soc Ser A Stat Soc. 2009;172(2):339-60.

15. Sauermann H, Roach M. Increasing web survey response rates in innovation research: An experimental study of static and dynamic contact design features. Res Policy. 2013;42(1):273-86.

16. Istaiteyeh R. Jordan higher education exports and circular migration. In: Knerr B, editor. Transfers from international migration: a strategy of economic and social stabilization at national and household level. Kassel, Germany: Kassel University Press; 2012. pp. 203-24.

17. Al-Nawafleh A, Zeilani RS, Evans C. After the doctorate: a qualitative study investigating nursing research career development in Jordan. Nurs Health Sci. 2013 Dec;15(4):423-9. PMID:23347142

18. Almalki M, FitzGerald G, Clark M. The nursing profession in Saudi Arabia: an overview. Int Nurs Rev. 2011 Sep;58(3):304-11. PMID:21848775

19. Kronfol NM. Delivery of health services in Arab countries: a review. East Mediterr Health J. 2012 Dec;18(12):1229-38. PMID:23301398

20. Nawafleh $\mathrm{H}$. The nursing profession in southern Jordan-challenges and recommendations for improvement. Contemp Nurse. 2013 Dec 21;3595-615. PMID:24359250

21. Abualrub RF. Nursing shortage in Jordan: what is the solution?J ProfNurs. 2007 Mar-Apr;23(2):117-20. PMID:17383605

22. Mrayyan MT. Nurse job satisfaction and retention: comparing public to private hospitals in Jordan. J Nurs Manag. 2005 Jan;13(1):40-50. PMID:15613093 